Published in final edited form as:

Exp Neurol. 1974 November ; 45(2): 332-340.

\title{
Narcolepsy-Cataplexy in a Female Dog
}

\author{
Merrill M. Mitler, Byron G. Boysen, Lewis Campbell, and William C. Dement ${ }^{1}$ \\ Stanford University School of Medicine, Stanford, California 94305, and University of \\ Saskatchewan College of Veterinary Medicine, Saskatoon, Saskatchewan, Canada
}

\section{Abstract}

Narcolepsy in human beings is a life-long illness afflicting 100,000-150,000 Americans. No current treatment for this neurological disorder is satisfactory and a definitive approach to the disease requires an animal model of narcolepsy. This report summarizes data on a female toy poodle which has a canine form of narcolepsy-cataplexy. At approximately 4 mo of age, the dog presented cataplectic attacks. Physical examination disclosed no systemic factors to account for such atonic episodes. Observation indicated that attacks were frequently partial, involving only the neck musculature and hind legs. However, such attacks could develop into complete cataplexy, causing postural collapse and areflexia, although extrinsic eye muscles and the muscles of respiration were spared. Presentation of food, water, or a plaything were the most frequent elicitors of attacks. During $41 \mathrm{hr}$ of EEG, EOG, and EMG monitoring in conjunction with behavioral observation, the dog exhibited normal polygraphic wakefulness, slow-wave sleep and REM sleep. Unambiguous sleep onset REM periods and cataplectic attacks were also observed. These pathological manifestations are analogous to those characteristic of human narcolepsy. The diagnosis of canine narcolepsy was further confirmed by two negative trials with neostigmine (ruling out myasthenia) and two positive trials with imipramine (cataplexy in human narcolepsy responds to imipramine treatment). The dog will be bred either with a littermate or a similarly afflicted male in an attempt to produce a population of afflicted dogs.

\section{INTRODUCTION}

\begin{abstract}
Narcolepsy in human beings is a well-defined neurological condition characterized by the postpubertal onset of sleep attacks, sleep paralysis, hypnagogic hallucinations, and cataplexy (15-18). The condition may also be diagnosed by the presence of sleep onset REM-sleep episodes in clinical sleep recordings as reported by Rechtschaffen and Dement (12). Narcolepsy is a life-long debilitating illness which afflicts between 100,000 and 150,000 Americans $(1,4)$. At the present time treatments are only partially effective and eventually palliative. As with other illnesses, a definitive approach to this serious and life-blighting illness will require understanding of the basic defect. Unfortunately such understanding is
\end{abstract}

\footnotetext{
${ }^{1}$ This research was supported by NIH Grant NS 10727 and Career Development Award MH 5804 to W.C.D. We wish to thank Benjamin Hart, School of Veterinary Medicine, University of California, Davis, Calif., and his co-workers for allowing us to use motion picture footage of dogs with cataplectic symptoms. We would also like to thank A. H. Rajput, University Hospital, University of Saskatchewan, Saskatoon, Saskatchewan, Canada, for seeing those movies and providing the final link in communication between the authors. Portions of the present data were reported at the 14th Annual Meeting of The Association for the Psychophysiological Study of Sleep, Jackson Hole, Wyo., June 5-9, 1974. Dr. Miller's present address is: Sleep Laboratory, Department of Psychiatry, Stanford University School of Medicine. Stanford, Calif. 94305.
} 
not likely to result from studies of human patient material in the forseeable future.

Furthermore, experimental induction of isolated narcoleptic symptoms in animals may be of only limited use as concluded by Mitler and Dement (11). However, there have recently been reports of narcoleptic-like conditions occurring in dogs ( 9 , and Benjamin Hart, personal communication) and a cat (9). These observations are of particular interest since major advances in the management and treatment of narcolepsy would certainly follow from studying animals afflicted with an analogous disease. We now report observations on a poodle which we have diagnosed as having the narcolepsy-cataplexy syndrome.

\section{MATERIAL AND METHODS}

The dog, a female toy poodle, was whelped in April of 1972 (litter of four; two males) and purchased in June 1972 at $7 \mathrm{wk}$ of age. No abnormalities were then noted by the veterinarian or owner. In August, while taken on vacation, the dog acutely developed what the owners described as "drop attacks," characterized by sudden onsets of weakness and falling, as if the dog were "fainting."

The dog was seen by several veterinarians and admitted to the University of Saskatchewan Veterinary Clinic in November 1972. It had all vaccinations and seemed otherwise healthy. There were no "personality" changes accompanying the onset of symptoms and previously trained responses such as "hand shaking" were normal. The diet had consisted of liver, fish, cream and other table foods. It was noted that attacks consistently occurred when the dog was eating.

Upon physical examination we found the dog to be mildly overweight. It also had a small umbilical hernia. Otherwise routine physical, neurological, and laboratory workups were unremarkable. Electrocardiograms before and during the hypotonic episodes revealed no pronounced changes in heart rate. Hypotonic episodes could not be initiated with the oculocardiac reflex. Induced swallowing by external palpation of the larynx did not precipitate hypotonia. Thus, swallowing epilepsy and vagal stimulation with syncope were not indicated. Cerebrospinal fluid was taken but the pressure was not measured due to the dangers associated with a cysternal tap. The pressure did not appear to be elevated, however, and the chemistry and cytology were unremarkable. The tentative diagnosis of narcolepsycataplexy was made by one of us (B.G.B.) and the dog was sent to Stanford University Medical Center for further evaluation.

\section{RESULTS}

Using metal wound clips as electrodes and a cable fixed at the nape of the neck with an elastic bandage, we recorded the dog's frontal, parietal, and occipital electronencephalogram as well as electrooculogram and nuchal electromyogram continuously for $41 \mathrm{hr}$ in concert with detailed behavioral observations. Throughout this recording period the dog was confined to an observation chamber which permitted nearly complete postural freedom. Figure 1 presents four polygraphic records representative of quiet wakefulness, drowsinesslight sleep, slow wave sleep, and REM sleep. We observed a generally low EMG activity throughout sleep. Thus, the atonia of REM sleep contrasted less sharply with the tonic EMG 
activity during sleep than one would expect in a normal animal. We also noted frequent disruptions of the normal wakefulness-sleep-REM sleep cycle by one or more of the following hypotonic episodes:

\section{Sleep-Onset REM Sleep Periods}

These were characterized by abrupt transitions from wakefulness to REM sleep with little or no intervening slow wave sleep. Figure 2 is an example of such a REM sleep onset. Note that in this case there was absolutely no intervening slow wave sleep.

\section{Partial Cataplectic Attacks}

These were the most frequent of the hypotonic episodes observed in the subject and were characterized by progressive weakness of the hindquarters. During these periods the dog became immobile, slowly sat down, and stared with a "glassy-eyed expression." Such partial attacks could last from several seconds to $1 \mathrm{~min}$. The dog seemed unable to move and yet retained sufficient tonus to sit with forelegs extended. Petting or talking loudly could frequently terminate the episode. Such partial attacks were most often seen while the dog played. If left undisturbed, this type of attack could develop into a complete atonic period. The tracings in Fig. 3 were taken during such a partial attack. Note that with our recording preparation there appeared to be no polygraphic abnormalities concomitant with partial attacks.

\section{Complete Cataplectic Attacks}

They were characterized by total flaccidity for intervals up to $90 \mathrm{sec}$. During such periods the dog was down on its side or stomach and appeared unable to move its head, neck or trunk. Eye movements, blinking, weak barking, chewing, and swallowing would appear. These atonic episodes sometimes had very sudden onsets, causing trie dog to collapse from a standing position. More often they developed from a partial attack. Such complete attacks occurred most frequently during feeding. They would occur, however, if successive partial attacks were interrupted and the dog was repeatedly made to stand on all four feet. During complete attacks, hind-leg tendon reflexes were profoundly attenuated (as elicited and measured by hand). Complete attacks began with a weakening of the hind legs and advanced to the forelimbs. Towards the end of such attacks, the first movements were of the hind legs and tail. It was also possible for the dog to bark and occasionally chew and swallow during complete attacks. In Fig. 4 the polygraphic tracings were taken at the onset of a complete cataplectic attack. Note the abrupt diminution of EMG activity, continuous wakefulnesslike low voltage, fast EEG and the waking eye movements. During these episodes the dog could make following eye movements and change direction of gaze without difficulty. The most frequent precipitants of complete attacks were associated with eating, drinking, mouthing toys, and chasing after people.

\section{"Bouncing" Episodes}

They were repetitive, short duration, cataplectic attacks. Each short attack appeared to be more profound than the partial attack since all limbs were simultaneously involved. However, the episodes were rapidly reversible and repetitive. "Bouncing" episodes most 
frequently occurred during eating and relaxed play. Figure 5 shows polygraphic tracings taken during such "bouncing." Points when the dog got up on all four limbs and collapsed again are marked with arrows. Because of the brevity of each atonic period, we were unable to tell which if any muscle groups were spared.

At no time did we see electroencephalographic abnormalities either isolated or in association with hypotonic periods. Thus, hypotonic epilepsy was not indicated. To rule out the possibility of canine myasthenia (10), $0.08 \mathrm{mg}$ of neostigmine was administered intramuscularly. No improvement in the frequency or duration of food induced attacks was observed. Two days later we repeated the neostigmine test with $0.15 \mathrm{mg}$ given intramuscularly. At this dose level we observed tonic pupillary constriction with the pupillary reflex intact which evidenced the cholinergic influence of neostigmine. However, there was no effect on the duration or frequency of hypotonic attacks.

To further substantiate the diagnosis of narcolepsy-cataplexy, we conducted two clinical trials with intravenous injections of imipramine, since imipramine and imipramine like compounds have been shown in human subjects to be effective anticataplectic agents $(6,13$, $14,18)$. In the first trial, attacks were repeatedly induced with small bits of meat. Then, 0.25 $\mathrm{mg} / \mathrm{kg}$ imipramine hydrochloride was administered. Subsequent meat induced cataplectic attacks were less frequent and of shorter duration. Within $45 \mathrm{~min}$, however, it seemed to be having as many attacks as before the drug. On a second trial, the dog was first behaviorally tested with respect to the elapsed time and number of cataplectic episodes associated with eating ten pieces of dog biscuit arranged in a row $3 \mathrm{~m}$ long. From baseline measurements, taken once a day for 6 days, the average elapsed time to eat all ten pieces was $5.56 \mathrm{~min}$ (SE $=.51)$ with an average of $3.67(\mathrm{SE}=.61)$ complete cataplectic collapses per trial. Thirty minutes after $0.4 \mathrm{mg} / \mathrm{kg}$ imipramine in $1 \mathrm{ml}$ saline plus dextrose vehicle she consumed all ten pieces in 3.17 min with two complete collapses. Two hours later the elapsed time was 4.27 min with four attacks. Three subsequent elapsed times and number of attacks following either no injection or injection of vehicle were equal to or greater than $4.43 \mathrm{~min}$ and five attacks respectively. Thus, it seems clear that like cataplexy in human beings, the dog's cataplectic attacks improved with imipramine.

\section{DISCUSSION}

We have been informed of two other dogs with symptomatology similar to the present case (unpublished observations of Benjamin Hart and co-workers at the University of California, Davis, Department of Veterinary Medicine, personal communication). In their clinical activities they treated a male standard poodle and a male Doberman pinscher. Both dogs had hypotonic symptoms identical to those of our miniature poodle as evidenced by Hart and colleagues' extensive motion picture records. The poodle was euthanized and the Doberman pinscher was treated with dextro-amphetamine to the satisfaction of the owner. The present case is also consistent with that of a dachshund reported by Knecht et al. (9). The dachshund's behavioral symptoms were quite similar to those of our poodle. As with our case, routine laboratory tests were unremarkable. With the dachshund, dextro-amphetamine was a partially effective but unsatisfactory treatment. Histology was apparently done on the whole brain. It would have been useful to have seen histological results for several sites in

Exp Neurol. Author manuscript; available in PMC 2014 August 29. 
the pontine and bulbar reticular formation, since current data implicate these areas in the elaboration of REM sleep motor inhibition $(7,8)$ and in cataplexy (e.g., 5, 11). The authors, however, only reported seven focal cellular accumulations in the right cerebrum. Our data as well as those of Hart and co-workers are at variance with symptomatology of the Siamese cat reported as a second case of narcolepsy by Knecht et al. (9). These workers observed that cat's narcoleptic episodes were characterized by salivation, incontinence, unresponsiveness and rigidity. The condition responded satisfactorily to dextro-amphetamine. From this second case report, it is difficult for us to see why a diagnosis of narcolepsy was made, since the seizurelike symptoms of salivation, incontinence, and rigidity are not found in human narcolepsy $(2,3,15,17,18)$. Epilepsy seems to better fit the symptoms; however, no mention is made of any therapeutic trials with anticonvulsants.

The prognosis for the present case of canine narcolepsy, as with cases of human narcolepsy, is extremely poor. Yet we are reluctant to continue treatment with imipramine because of the high probability of the dog developing tolerance and the dangers of serious side effects. Furthermore, since the dog is a potentially fertile female, we plan to try no experimental treatments until she has been bred. Popular accounts of the dog have appeared in newspapers nationwide and resultant inquiries by readers have disclosed several similarly afflicted dogs. We are now in a position to breed the present dog with a fertile, afflicted male as well as with a male littermate. Such matings may start a population of animals with the disorder. With a supply of narcoleptic dogs, neurological experimentation can begin in earnest on the disease. $^{2}$

\section{References}

1. Dement W, Carskadon M, Ley R. The prevalence of narcolepsy II. Sleep Res. 1973; 2:147.

2. Dement W, Guilleminault C, Mitler M. Cataplectic attack: polygraphic recording in man and experimental induction in cat. Neurology. 1973; 23:403-404.

3. Dement, W.; Rechtschaffen, A. Narcolepsy: polygraphic aspects, experimental and theoretical considerations. In: Gastaut, H.; Lugaresi, E.; Berti-Ceroni, G.; Coccogna, G., editors. The Abnormalities of Sleep in Man. A. Gaggi; Bologna, Italy: 1968. p. 147-164.

4. Dement W, Zarcone V, Varner V, Hoddes E, Nassau S, Jacobs B, Brown J, McDonald A, Horan K, Glass R, Gonzales P, Friedman E, Phillips R. The prevalence of narcolepsy. Sleep Res. 1972; 1:148.

5. George R, Haslett W, Jenden D. A cholinergic mechanism in the brainstem reticular formation: Induction of paradoxical sleep. Int J Neuropharmacol. 1964; 3:541-552. [PubMed: 14344492]

6. Guilleminault C. La narcolepsie. Rev Neuropsychiatr Infant. 1972; 20:857-861. [PubMed: 4346494]

7. Henley K, Morrison A. Release of organized behavior during desynchronized sleep in cats with pontine lesions. Psychophysiology. 1969; 6:245.

8. Jouvet M. The role of monoamines and acetylcholine-containing neurons in the regulation of the sleep-waking cycle. Ergeb Physiol. 1972; 64:166-307. [PubMed: 4403272]

9. Knecht C, Oliver J, Redding R, Selcer R, Johnson G. Narcolepsy in a dog and a cat. J Amer Vet Med Assoc. 1973; 162:1052-1053. [PubMed: 4736237]

10. Lorenz MA, deLahunta, Alstrom D. Neostigmine-responsive weakness in the dog similar to myasthenia gravis. J Amer Vet Med Assoc. 1972; 161:795-800. [PubMed: 5074261]

\footnotetext{
${ }^{2}$ At the time of galley correction (September 20,1974$)$ we are studying a second dog (10 mo old, female, toy poodle) with cataplectic attacks. As with the first dog, symptoms were noted before 5 mo of age. Polygraphic records on the second dog show wakefulness, drowsiness-light sleep, slow wave sleep and REM sleep as well as all of the pathological patterns described here.
} 
11. Mitler M, Dement W. Cataplectic-like behavior in cats after micro-injections of carbachol in pontine reticular formation. Brain Res. 1974; 68:335-343. [PubMed: 4857063]

12. Rechtschaffen, A.; Dement, W. Studies on the relation of narcolepsy, cataplexy, and sleep with low voltage random EEG activity. In: Kety, S.; Evarts, E.; Williams, H., editors. Sleep and Altered States of Consciousness. Williams and Wilkins; Baltimore: 1967. p. 488-505.

13. Roth B. Pathophysiologische Mechanismen der Narkolepsie und der Hypersomnia. Z EEG-EMG. $1971 ; 2: 153-162$.

14. Roth B, Faber J, Nevsimalova A. Clinical and polygraphic study of the effect of a new imidazoquinazoline derivative in narcolepsy-cataplexy. The relationship between the antidepressant and the anticataplectic effects of the drug. Act Nerv Super (Praha). 1972; 14:35-39. [PubMed: 4336749]

15. Sours J. Narcolepsy and other disturbances in the sleep-waking rhythms: a study of 115 cases with review of the literature. J Nerv Ment Dis. 1963; 137:525-542. [PubMed: 14087671]

16. Yoss R, Daly D. Criteria for the diagnosis of the narcoleptic syndrome. Proc Staff Meet Mayo din. 1957; 32:320-328.

17. Yoss R, Daly D. On the treatment of narcolepsy. Med Clin North Amer. 1968; 52:781-787. [PubMed: 5268119]

18. Zarcone V. Narcolepsy. N Engl J Med. 1973; 288:1156-1166. [PubMed: 4349356] 


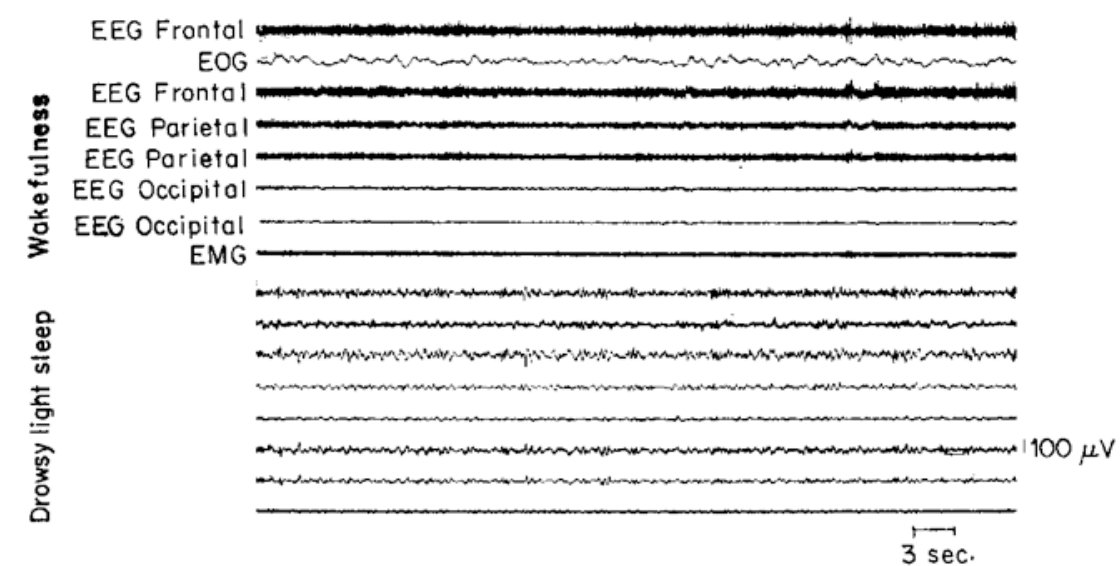

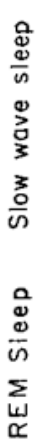

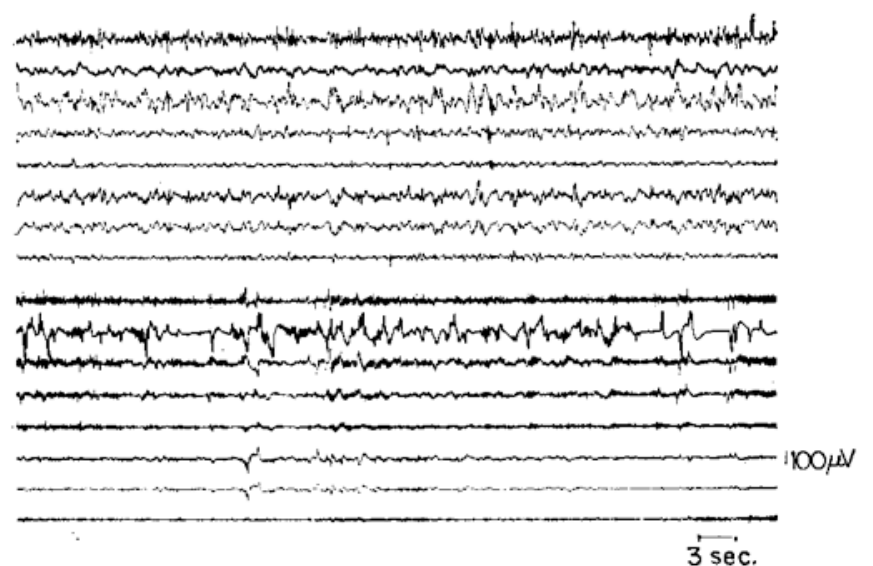

Fig. 1.

Four polygraphic tracings representative of the states of wakefulness, slow wave sleep and REM sleep: (a) Wakefulness. During this sample the animal was sitting quietly with head up making occasional head and eye movements. (b) Drowsiness-light sleep. During these tracings the animal was sitting with head down and eyes closed. Note the tonic presence of EMG activity. (c) Slowwave sleep. During these traces the animal was curled up, eyes were closed and respiration was even. Note the frequent high voltage slow waves and the virtual absence of EMG activity. (d) REM sleep. During these tracings the animal was curled up and the eyes moved underneath closed or partially closed eyelids, muscles appeared flaccid but with occasional fasicular twitches. This particular REM episode followed a period of SWS. 


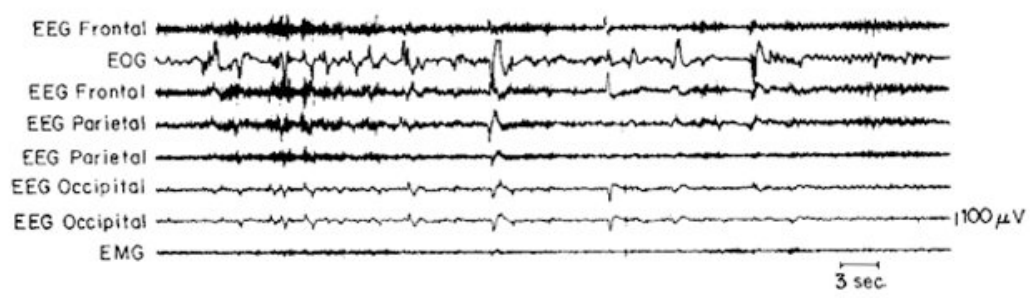

Fig. 2.

Sleep-onset REM period. These polygraphic tracings were taken while the animal made an abrupt transition from quiet but alert wakefulness to REM sleep. Note that there are large eye movements throughout the entire tracing. EMG activity diminishes abruptly yet EEG desynchronization is continuous throughout the record. 


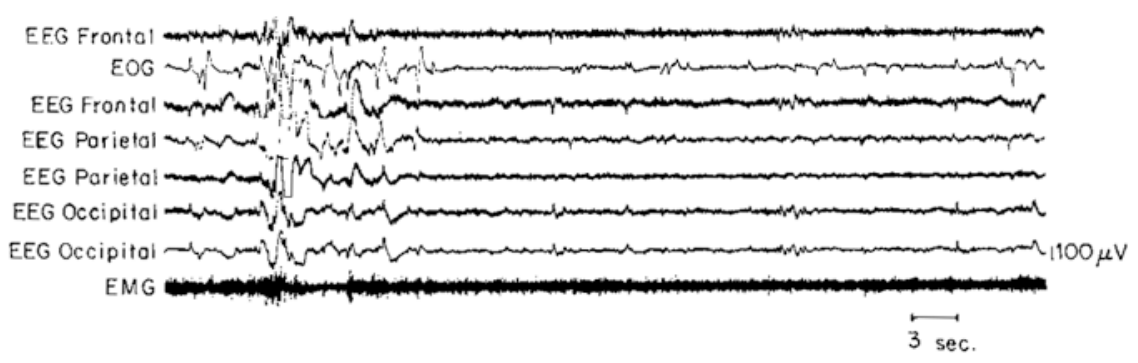

Fig. 3.

Partial attack. These polygraphic tracings were taken while the animal was sitting and staring with a "glassy-eyed" expression. The animal could make following eye movements and could hold its head up as evidenced by the tonically active nuchal EMG activity. 


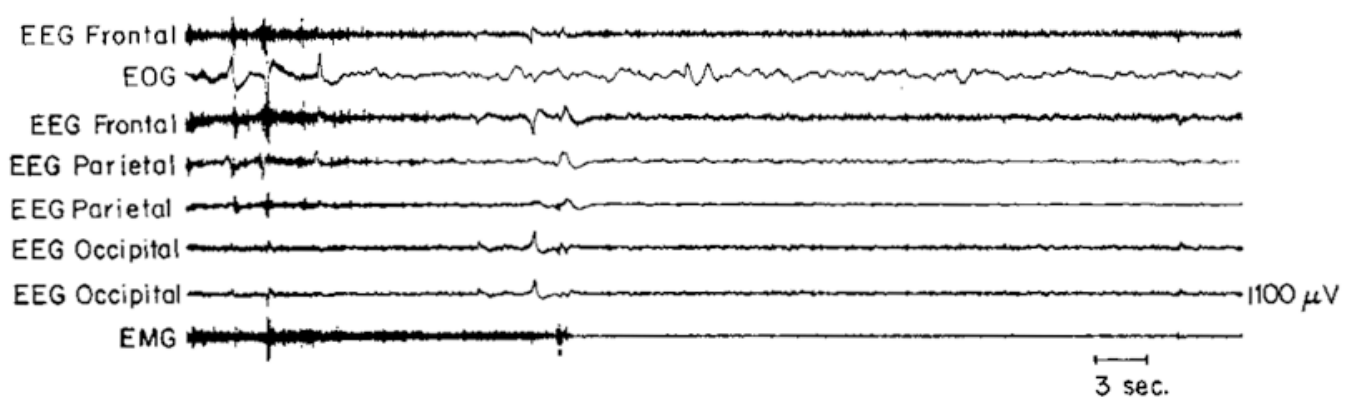

Fig. 4.

Cataplexy. This is an example of a cataplectic attack. Note the abrupt diminution of EMG activity, the absence of EEG changes, and no clear change in EOG. The animal was sitting quietly when its head dropped to the floor. The eyes remained open, but the animal appeared totally atonic. 


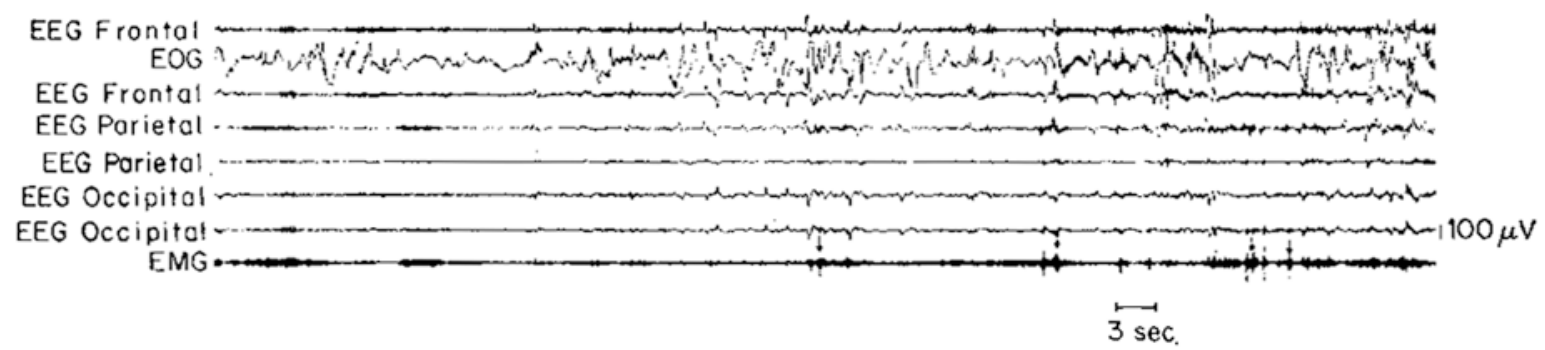

Fig 5.

Repeated short-duration cataplectic attacks ("bouncing"). These tracings were taken during a period of short duration, repeated cataplectic attacks which were characterized by the animal bouncing up and down, first standing, then collapsed, then standing again in rapid succession. These abrupt changes in posture are evidenced by the frequent bursts of EMG activity. Examples are marked with arrows. 